\title{
Search for vertical stratification of metals in atmospheres of blue horizontal-branch stars ${ }^{\star}$
}

\author{
V. R. Khalack ${ }^{1}$, F. LeBlanc ${ }^{1}$, B. B. Behr ${ }^{2, \star \star}$, G. A. Wade ${ }^{3}$, and D. Bohlender ${ }^{4}$ \\ 1 Département de Physique et d'Astronomie, Université de Moncton, Moncton, N.-B., E1A 3E9, Canada \\ e-mail: khalakv@umoncton.ca \\ 2 Department of Astronomy, University of Texas at Austin, 1 University Station C1400, Austin TX 78712-0259, USA \\ 3 Department of Physics, Royal Military College of Canada, PO Box 17000 stn "FORCES", Kingston, Ontario, K7K 4B4, Canada \\ ${ }^{4}$ National Research Council of Canada, Herzberg Institute of Astrophysics, 5071 West Saanich Road, Victoria, BC, V9E 2E7, Canada
}

Received 15 August 2007 / Accepted 19 October 2007

\begin{abstract}
Context. The observed abundance peculiarities of many chemical species relative to the expected cluster metallicity in blue horizontalbranch (BHB) stars presumably appear as a result of atomic diffusion in the photosphere. The slow rotation (typically $v \sin i<$ $10 \mathrm{~km} \mathrm{~s}^{-1}$ ) of BHB stars with effective temperatures $T_{\text {eff }}>11500 \mathrm{~K}$ supports this idea since the diffusion mechanism is only effective in a stable stellar atmosphere.

Aims. In this work we search for observational evidence of vertical chemical stratification in the atmospheres of six hot BHB stars: B84, B267 and B279 in M 15 and WF2-2541, WF4-3085 and WF4-3485 in M 13.

Methods. We undertake an abundance stratification analysis of the stellar atmospheres of the aforementioned stars, based on acquired Keck HIRES spectra.

Results. We have found from our numerical simulations that three stars (B267, B279 and WF2-2541) show clear signatures of the vertical stratification of iron whose abundance increases toward the lower atmosphere, while the other two stars (B84 and WF4-3485) do not. For WF4-3085 the iron stratification results are inconclusive. B267 also shows a signature of titanium stratification. Our estimates for radial velocity, $v \sin i$ and overall iron, titanium and phosphorus abundances agree with previously published data for these stars after taking the measurement errors into account. The results support the hypothesis regarding the efficiency of atomic diffusion in the stellar atmospheres of BHB stars with $T_{\text {eff }}>11500 \mathrm{~K}$.
\end{abstract}

Key words. stars: atmospheres - stars: horizontal-branch - stars: chemically peculiar

\section{Introduction}

According to the current understanding of stellar evolution, the horizontal-branch (HB) stars are post-main sequence stars that burn helium in their core and hydrogen in a shell (e.g. Moehler 2004). In this paper we consider the HB stars that are located in the blue part of the HB, to the left of the RR Lyrae instability strip. Most researchers call them blue horizontal-branch (BHB) stars to distinguish them from the red horizontal-branch (RHB) stars, which exhibit different observational properties. Sandage \& Wallerstein (1960) have found from analysis of the colour-magnitude diagrams of globular clusters ${ }^{1}$ that the HB generally becomes bluer with decreasing metallicity. Derived masses of the cool $\left(T_{\text {eff }}<11500 \mathrm{~K}\right)$ BHB stars in the globular cluster NGC 6388 (Moehler \& Sweigart 2006) are in a good agreement with the predictions of canonical HB evolution, except for the hot BHB stars with $T_{\text {eff }}>11500 \mathrm{~K}$, where the estimated stellar masses seem to be lower than the canonical values.

The Hertzsprung-Russell diagrams of some globular clusters show long blue tails (an extension of the HB), populated by

* Full Table 3 is only available in electronic form at http://www . aanda.org

$\star \star$ Current address: US Naval Observatory, 3450 Massachusetts Avenue NW, Washington DC 20392.

${ }^{1}$ Most of the known BHB stars are found in globular clusters. very hot BHB stars and extreme horizontal branch (EHB) stars. Published data on the BHB stars argue that the hot BHB stars show remarkable differences in physical properties when compared to the cool BHB stars. Using high-precision photometry of stars in M 13, Ferraro et al. (1998) have found gaps in the distribution of stars along the blue tail. One of these gaps, labeled as G1, is located at $T_{\text {eff }} \sim 11000-12000 \mathrm{~K}$. Grundahl et al. (1998) used the results of Strömgren $u v b y \beta$-photometry finding good agreement between the theoretical prediction of stellar evolution models and the observed location of BHB stars, except for the hot BHB stars, whose $u$-magnitudes are brighter than predicted. It appears that this $u$-jump is observed for the hot BHB stars and coincides with the temperature range of the G1 gap in M 13. Similar $u$-jumps have also been found for other globular clusters (Grundahl et al. 1999). For the hot BHB with effective temperatures up to $20000 \mathrm{~K}$, the surface gravities derived from the fits of Balmer and helium line profiles appear to be lower than the predictions of stellar evolution models, while the gravities derived for the stars outside this temperature range are in good agreement with theoretical predictions (Moehler et al. 1995, 1997a,b, 2003). The stellar rotation velocity distribution of BHB stars also appears to have a discontinuity at $T_{\text {eff }} \simeq 11500 \mathrm{~K}$ (Peterson et al. 1995; Behr et al. 2000a; Recio-Blanco et al. 2004), indicating that the hotter stars show modest rotation with $v \sin i<10 \mathrm{~km} \mathrm{~s}^{-1}$, while the cooler stars rotate more rapidly 
Table 1. Journal of Keck+HIRES spectroscopic observations of the selected hot BHB stars from Behr (2003b).

\begin{tabular}{lcccccc}
\hline \hline Cluster/Star & $\begin{array}{c}\text { HJD } \\
2450000+\end{array}$ & $\begin{array}{c}\text { Exposure } \\
\text { time }(\mathrm{s})\end{array}$ & $\begin{array}{c}S / N \\
\text { Coverage } \\
(\AA)\end{array}$ & $\begin{array}{c}\text { Seeing } \\
(\operatorname{arcsec})\end{array}$ & $\begin{array}{c}\text { Slit' width } \\
(\operatorname{arcsec})\end{array}$ \\
\hline M 13/WF2-2541 & 1046.7902 & $3 \times 1500$ & 44 & $3885-6292$ & 0.90 & 0.86 \\
M 13/WF4-3085 & 1052.7338 & $3 \times 1200$ & 37 & $3888-5356$ & 1.10 & 0.86 \\
M 13/WF4-3485 & 1053.7793 & $3 \times 1200$ & 34 & $3888-5356$ & 0.90 & 0.86 \\
M 15/B84 & 1053.9024 & $4 \times 1400$ & 34 & $3888-5356$ & 0.80 & 0.86 \\
M 15/B267 & 1053.9731 & $4 \times 1400$ & 26 & $3888-5356$ & 0.80 & 0.86 \\
M 15/B279 & 1053.8312 & $4 \times 1400$ & 34 & $3888-5356$ & 0.90 & 0.86 \\
\hline
\end{tabular}

on average. Comprehensive surveys of abundances also show that the hot BHB stars have abundance anomalies when compared to the cool BHB stars in the same cluster (Glaspey et al. 1989; Grundahl et al. 1999; Behr et al. 1999, 2000b, Behr 2003a; Fabbian et al. 2005; Pace et al. 2006).

The observed phenomena such as the low gravity, photometric jumps and gaps, abundance anomalies and slow rotation suggest that atomic diffusion could be important in the stellar atmospheres of hot BHB stars. Atomic diffusion arises from the competition between radiative acceleration and gravitational settling. This can produce a net acceleration on atoms and ions, which results in their diffusion through the atmosphere (Michaud 1970). In order for atomic diffusion to produce a vertical stratification of the abundances of particular elements, the stellar atmosphere must be hydrodynamically stable. According to Landstreet (1998), photospheric convection should be very weak at the effective temperatures of BHB stars. Theoretical atmospheric models of Hui-Bon-Hoa et al. (2000) showed that the observed photometric jumps and gaps for hot BHB stars can be explained by elemental diffusion in their atmosphere. Behr (2003b) has shown that adoption of a microturbulent velocity of 0 or $1 \mathrm{~km} \mathrm{~s}^{-1}$ provides the best fit to line strengths in the spectra of hot BHB stars. This fact supports the proposal that strong velocity fields are not present in the atmospheres of hot BHB stars.

While synthesizing spectral line profiles, Khalack et al. (2007) have recently found vertical abundance stratification of sulfur in the atmosphere of the field BHB star HD 135485. In this paper we also attempt to detect signatures of vertical abundance stratification of elements from line profile analyses of several other BHB stars for which we have appropriate data. Together with the data on stratification of the sulfur abundance in HD 135485, new positive results would provide a convincing argument in favour of efficient atomic diffusion in the atmospheres of hot BHB stars. In Sect. 2 we discuss the properties of the acquired spectra, while in Sect. 3 we describe details concerning the simulation routine and adopted atmospheric parameters for the program stars. The evidence for vertical stratification of some chemical species is given in Sect. 4, while the estimation of mean abundances and velocities is described in Sect. 5. A discussion follows in Sect. 6.

\section{Observations}

In this paper we have selected hot BHB stars from the list of objects published by Behr (2003b) and which have comparatively high signal-to-noise ratio $(S / N)$ spectra available. Spectroscopic observations of the selected stars were undertaken in August 1998 with the Keck I telescope and the HIRES spectrograph. The journal of spectroscopic observations is shown in Table 1 where individual columns give the object identification, the heliocentric Julian Date of the observation, the exposure time, the $S / N$ per pixel, the spectral coverage, the size of
Table 2. Parameters of stellar atmospheres for the selected hot BHB stars from Behr (2003b).

\begin{tabular}{lcccc}
\hline \hline Cluster/Star & $\begin{array}{c}T_{\text {eff }} \\
(\mathrm{K})\end{array}$ & $\begin{array}{c}\log g \\
(\mathrm{dex})\end{array}$ & $\begin{array}{c}\xi \\
\left(\mathrm{km} \mathrm{s}^{-1}\right)\end{array}$ & $\begin{array}{c}V_{\mathrm{r}} \\
\left(\mathrm{km} \mathrm{s}^{-1}\right)\end{array}$ \\
\hline M13/WF2-2541 & 13000 & 4.0 & 0.0 & -257.5 \\
M13/WF4-3085 & 14000 & 4.0 & 0.0 & -255.7 \\
M13/WF4-3485 & 13000 & 4.0 & 0.0 & -246.8 \\
M15/B84 & 12000 & 3.5 & 0.5 & -108.2 \\
M15/B267 & 11000 & 3.5 & 0.0 & -114.4 \\
M15/B279 & 11000 & 3.5 & 0.9 & -104.4 \\
\hline
\end{tabular}

the seeing disk (FWHM) and the size of the $\mathrm{C} 1$ slit that provides a spectral resolution of $R=\lambda / \delta \lambda=45000$. For the aforementioned stars, Behr (2003b) has found that the underfilling of the slit should not change the estimated spectral resolution by more than $4-7 \%$.

The package of routines developed by McCarthy (1990) for the FIGARO data analysis package (Shortridge 1993) was employed to process the spectra. A comprehensive description of the data acquisition and reduction procedure is presented by Behr (2003b). This followed a standard prescription with bias subtraction, flat-fielding, order extraction, and wavelength calibration from thorium-argon comparison lamp observations. To minimize the potential distortion of narrow spectra features, cosmic ray hits were identified and removed by hand.

\section{Line profile simulations}

\subsection{Stellar atmosphere parameters}

The line profile simulations were performed with the ZEEMAN2 spectrum synthesis code (Landstreet 1988; Wade et al. 2001). The stellar atmosphere models were calculated with the PHOENIX code (Hauschildt et al. 1997) assuming LTE (Local Thermodynamic Equilibrium) and using the stellar atmosphere parameters extracted from Behr (2003b) and listed in Table 2. In calculating the stellar atmosphere models for program stars, we have used solar metallicity with the enhanced iron and depleted helium abundances derived by Behr (2003b). The depleted helium abundance has also been taken into account during line profile simulations using ZEEMAN2. We used Gaussian instrumental profiles with widths derived from the comparison arc spectra.

To simulate the spectra of BHB stars, Behr (2003b) initially adopted a microturbulent velocity $\xi=2 \mathrm{~km} \mathrm{~s}^{-1}$ and subsequently updated it during the simulation routine according to the results of his model fits. He has obtained best fit values of $\xi$ from 0 to $0.9 \mathrm{~km} \mathrm{~s}^{-1}$ for the BHB stars studied here (see Table 2). Since we search for possible vertical abundance stratification, our results can be affected by microturbulence. To estimate this influence we have adopted here two different microturbulent velocities $\xi=$ 0 and $2 \mathrm{~km} \mathrm{~s}^{-1}$ for our simulations. 
Table 3. List of iron spectral lines used for the abundance analysis.

\begin{tabular}{|c|c|c|c|c|c|c|c|c|c|c|}
\hline$\lambda, \AA$ & $\log g f$ & $E_{i}, \mathrm{~cm}^{-1}$ & $\log \gamma_{\mathrm{rad}}$ & Ref. & \multicolumn{5}{|c|}{ Object name } & \\
\hline & & Fe II & & & WF2-2541 & WF4-3085 & WF2-3585 & $\overline{B 84}$ & B267 & B279 \\
\hline 4122.668 & -3.300 & 20830.58 & 8.49 & $\bar{R} \& U$ & $\ldots$ & $\mathrm{X}$ & $\cdots$ & $\mathrm{X}$ & $\ldots$ & $\ldots$ \\
\hline 4128.748 & -3.578 & 20830.58 & 8.61 & $R \& U$ & $\ldots$ & $\mathrm{x}$ & $\ldots$ & $\ldots$ & $\ldots$ & $\mathrm{x}$ \\
\hline 4173.461 & -2.617 & 20830.58 & 8.61 & $R \& U$ & $\mathrm{x}$ & $\mathrm{x}$ & $\mathrm{x}$ & $\mathrm{x}$ & $\mathrm{x}$ & $\ldots$ \\
\hline 4177.618 & -3.776 & 73395.93 & 8.61 & $R \& U$ & $\ldots$ & $\mathrm{x}$ & $\ldots$ & $\mathrm{x}$ & $\ldots$ & $\mathrm{x}$ \\
\hline 4177.692 & -3.449 & 20516.96 & 8.61 & $R \& U$ & . & $\mathrm{x}$ & $\ldots$ & $\mathrm{x}$ & $\ldots$ & $\mathrm{x}$ \\
\hline 4178.862 & -2.535 & 20830.58 & 8.49 & $R \& U$ & $\mathrm{x}$ & $\mathrm{x}$ & $\mathrm{x}$ & $\mathrm{x}$ & $\ldots$ & $\mathrm{x}$ \\
\hline 4184.261 & -1.938 & 90397.87 & 8.35 & $R \& U$ & $\ldots$ & $\mathrm{x}$ & $\ldots$ & $\ldots$ & $\ldots$ & $\ldots$ \\
\hline
\end{tabular}

Table 3 is presented in full in electronic form. A portion is shown here for guidance and content.

\subsection{Procedure}

We examined the spectrum of each star to establish a line list suitable for abundance and stratification analysis. The line identification was performed using the VALD-2 (Kupka et al. 1999; Ryabchikova et al. 1999), Pickering et al. (2001) and Raassen \& Uylings ${ }^{2}$ (1998) line databases. For all of the program stars the best represented element (with a number of readily visible line profiles) is iron. Some stars also show Ti II or $\mathrm{P}$ II lines. Therefore iron, titanium and phosphorus were selected for analysis of their possible vertical abundance stratification. For Fe II lines, we extracted atomic data from Raassen \& Uylings (1998), while for P II lines we used VALD-2. Atomic data for Ti II lines were taken from Pickering et al. (2001).

The ZEEMAN2 code has been modified (Khalack \& Wade 2006) to allow for an automatic minimization of the model parameters using the downhill simplex method (Press et al. 1992). The minimization routine finds the global minimum of the $\chi^{2}$ function, which is specified as the measure of differences between simulated and observed line profiles. The relatively poor efficiency of the downhill simplex method, requiring a large number of function evaluations, is a well known problem. However, repeating the minimization routine several times in the vicinity of a supposed minimum in the chosen parameter space allows us to verify if the method converges to the global minimum (for more details about this minimization routine see Khalack et al. 2007).

To search for the presence of abundance stratification, we have estimated the abundance of a chemical element from an independent analysis of each selected line profile. This method operates with three free model parameters (the element's abundance, the radial velocity $V_{\mathrm{r}}$ and $v \sin i$ ) that are derived from each line profile using the aforementioned automatic minimization routine. To analyse the vertical abundance stratification in this method we build the scale of optical depths $\tau_{5000}$ for the list of selected line profiles. First, we calculate the line optical depth $\tau_{\ell}$ in the line core for every layer of the stellar atmosphere model. Next, we suppose that each analyzed profile is formed mainly at $\tau_{\ell}=1$, which corresponds to a particular layer of the stellar atmosphere with respective continuum optical depth $\tau_{5000}$. All simulations are performed with stellar atmosphere models that contain 50 layers.

In general, we have selected for our analysis lines found to be free of predicted or inferred blends. However, if a blend is from a line of the same element that forms the main line profile, such a line was also included in our simulation. When a simulated line profile results in a radial velocity which differs significantly (more than $2 \mathrm{~km} \mathrm{~s}^{-1}$ ) from the average $V_{\mathrm{r}}$ for the analysed star, we exclude such a line from further consideration.

\footnotetext{
${ }^{2}$ ftp://ftp.wins.uva.nl/pub/orth
}

The difference in radial velocity may be evidence of line misidentifications or inaccurate line wavelengths. Atomic data (and sources) for the final list of iron lines selected for our study are given in Table 3.

\section{Vertical abundance stratification}

Applying the technique described in Sect. 3.2, we have attempted to determine if the iron abundance is vertically stratified in the atmospheres of the six selected BHB stars. For comparison, we have also investigated the possible vertical stratification of titanium and phosphorus for some BHB stars, where these elements are represented by a sufficient number of spectral lines.

All of the selected BHB stars are slowly rotating and have sharp absorption lines that result in only 8 to 13 spectral bins per line profile. This fact, together with the $S / N$ and the uncertainties in the atomic data, are the main contributors to errors in the abundance inferred from a single line. This makes the detection of weak vertical abundance variations difficult.

Our abundance analysis for $\xi=0 \mathrm{~km} \mathrm{~s}^{-1}$ shows that in the atmospheres of four BHB stars (B267, B279, WF4-3085 and WF2-2541) the iron abundance generally increases towards the deeper atmospheric depths (see Figs. 1-5). It should be noted that the range of optical depths diagnosed by the iron lines is much smaller in the stars B279 and WF2-2541 than in the other two stars shown here. To estimate the stratification profile of the iron abundance we fit the data with a straight line using a leastsquare algorithm. We have also checked the dependence of each element's abundance with respect to the lower level excitation potential $E_{i}$ for the sample of analyzed lines (see as an example Fig. 3). Slopes of the linearly approximated dependence of each element's abundance with respect to $\log E_{i}$ and $\log \tau_{5000}$ are given in Table 4 for the case of zero microturbulent velocity. Table 4 shows a clear correlation between the slope of the abundance versus $\log \tau_{5000}$ and $\log E_{i}$ for the elements considered in each star. This correlation strongly suggests that the obtained stratification is physical and not due to uncertainties in the description of the temperature profile of the stellar atmosphere.

The detected stratification of iron, obtained in some of the stars studied here, is far too large ( $>2 \mathrm{dex}$ ) to be interpreted as the result of measurement errors. Our stellar atmosphere models were calculated taking into account the enhanced iron abundance and helium depletion (Behr 2003b) and the error in estimating the iron abundances, for a given model atmosphere, is expected to be less than 0.2 dex. Meanwhile, Khan \& Shulyak (2007) have shown that using atmospheric models with varying Fe abundance (from one to ten times solar) can modify the abundances inferred from observed line profiles by up to \pm 0.25 dex.

From the results in Table 4 we can conclude that no detectable iron stratification exists in WF4-3485 and B84. Two 
a)

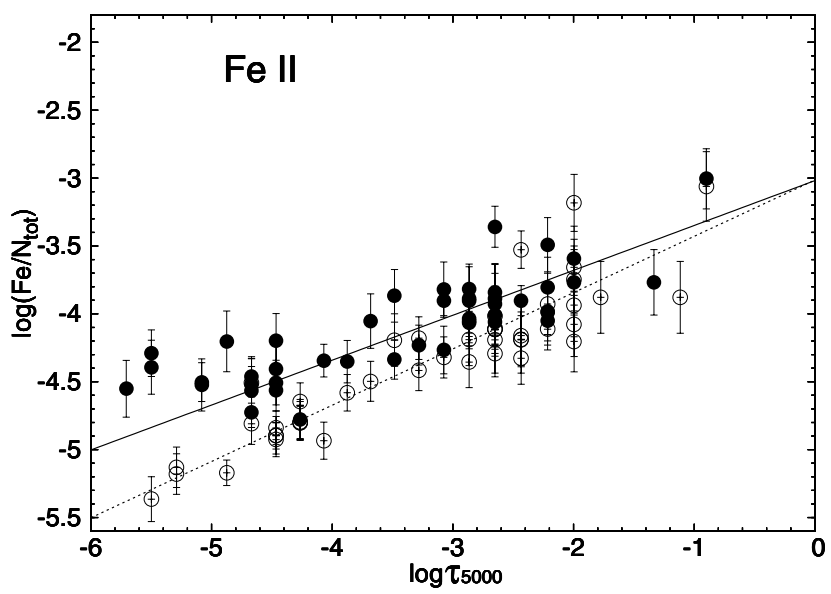

b)

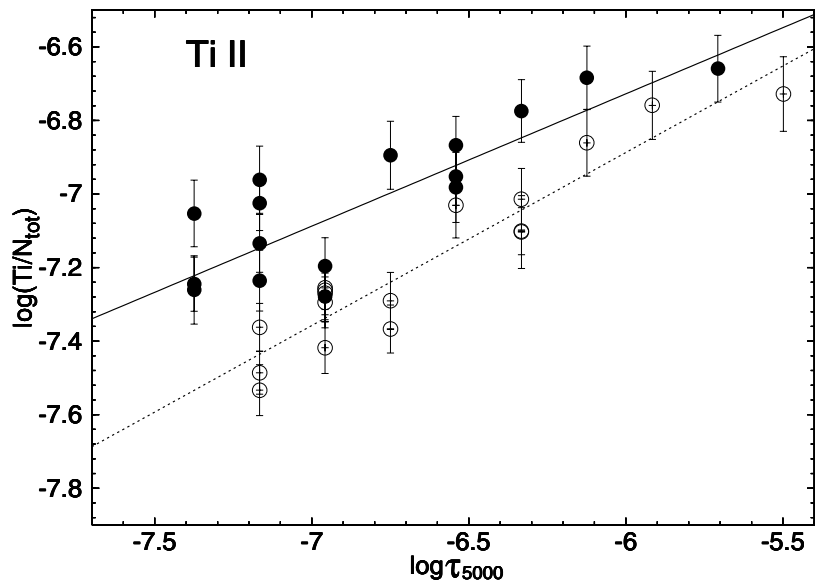

Fig. 1. Abundance estimates from the analysis of a) Fe II and b) Ti II lines as a function of line (core) formation optical depth assuming $\xi=$ $0 \mathrm{~km} \mathrm{~s}^{-1}$ (filled circles) and $\xi=2 \mathrm{~km} \mathrm{~s}^{-1}$ (open circles) for B267. The solid and dashed lines approximate the filled and open circles respectively with straight line using the least-square algorithm.

a)

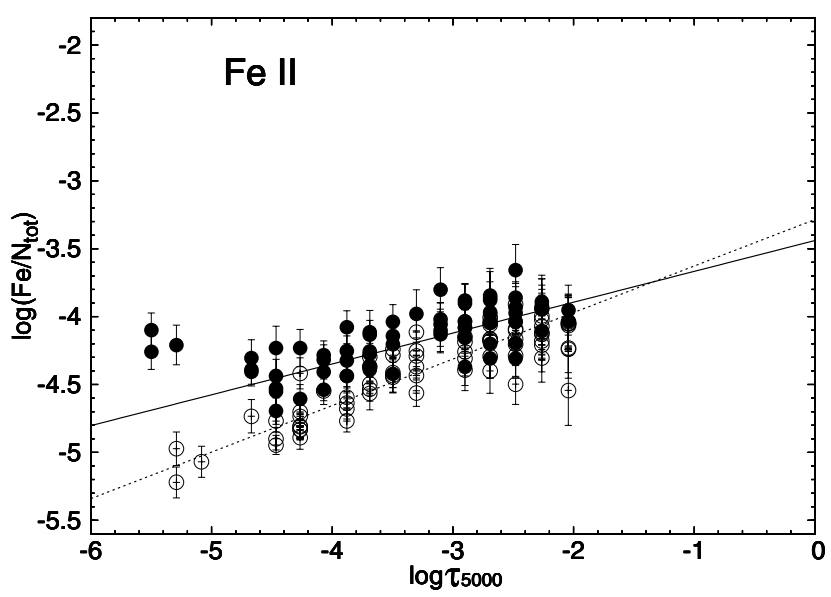

b)

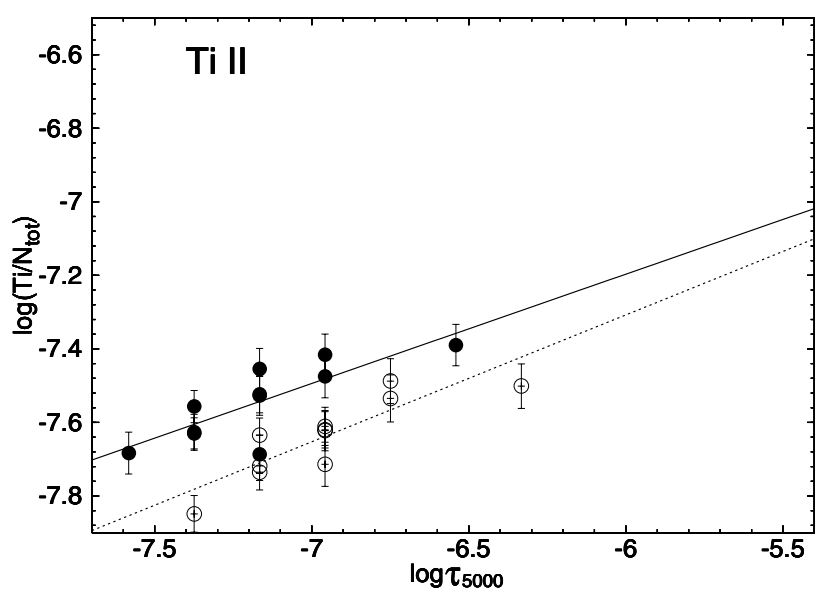

Fig. 2. The same as in Fig. 1, but for a) Fe II and b) Ti II lines extracted from the B279 spectrum.

stars (B267 and B279) show quite large slopes of iron abundance with respect to both $\log E_{i}$ and $\log \tau_{5000}$. The corresponding slopes for the stars WF2-2541 and WF2-3085 are smaller but still statistically significant. The least significant of these slopes is that of the abundance versus $\log E_{i}$ for WF2-3085 which has only approximately a $3 \sigma$ value.

Another factor that must be evaluated that could mimic stratification is an error in the effective temperature of the underlying atmospheric model used. To verify the potential importance of this factor, we calculated the Fe stratification with models with an effective temperature higher and lower by $1000 \mathrm{~K}$ from the $T_{\text {eff }}$ values listed in Table 2 . We also calculated the stratification with models assuming solar $\mathrm{He}$ and $\mathrm{Fe}$ abundances to evaluate the effect of this change on the inferred stratification profiles. Our simulations show that models with higher $T_{\text {eff }}$ and models with solar abundances usually slightly decrease the slope of the abundance with respect to $\log E_{i}$, while models with lower $T_{\text {eff }}$ increase this slope for all elements. In the case of iron in WF4-3085, the model with higher $T_{\text {eff }}$ and the model with solar abundances result in a negligible slope of its abundance versus $\log E_{i}$. Therefore, the results are not sufficient to report unambiguous detection of vertical stratification of iron in WF4-3085. The slopes for iron found for the other three stars (B267, B279 and WF-2541) are still significant in all these models, and stratification is therefore confirmed.

The two BHB stars (B84 in M 15 and WF4-3485 in M 13) which do not show any signs of stratification of their iron abundances are not different from the other stars with regards to their stellar atmosphere characteristics and rotation (see Table 2). However, these two stars possess very small titanium and phosphorus abundances as compared to the other stars studied here. Their spectra have very weak or invisible Ti II and P II lines. Their iron abundance is also close to the solar value, at least for $\xi=0 \mathrm{~km} \mathrm{~s}^{-1}$ (see Table 5).

We observe an upturn in the iron abundance obtained assuming $\xi=0 \mathrm{~km} \mathrm{~s}^{-1}$ at low optical depths for some of the stars studied (e.g. Figs. 1a, 2a, 4a, 5a). The points on the figures corresponding to the upturn feature are the strong Fe II lines and are not taken into account during the least-square fit of the data. To estimate the influence of microturbulence we have performed an abundance analysis with $\xi=2 \mathrm{~km} \mathrm{~s}^{-1}$, which leads to elimination of the upturn (see, for example, Fig. 1a). Performing a set of simulations with different microturbulent velocities, we have determined the minimum value of the microturbulence $\left(\xi_{\min }\right)$ for which the upturn disappears for each star studied. These values are reported in Table 5. As the inclusion of microturbulent 
a)

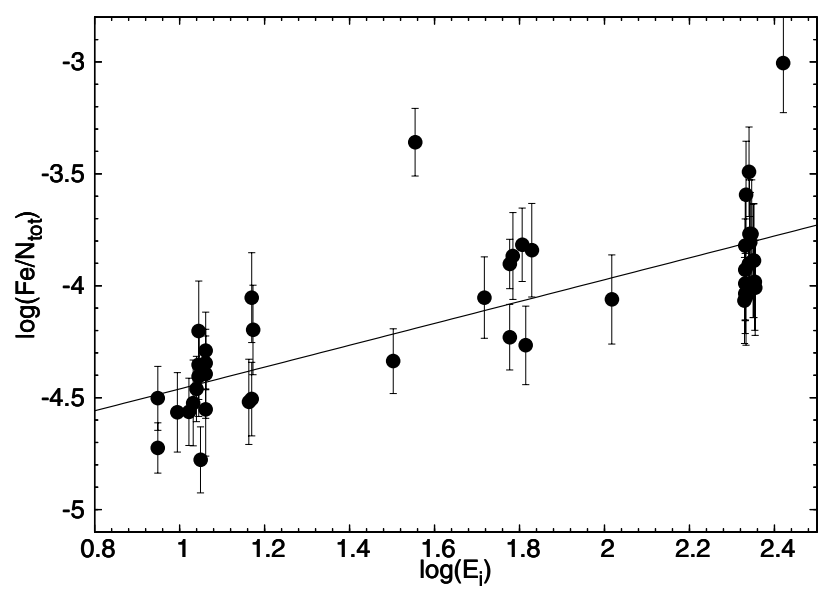

b)

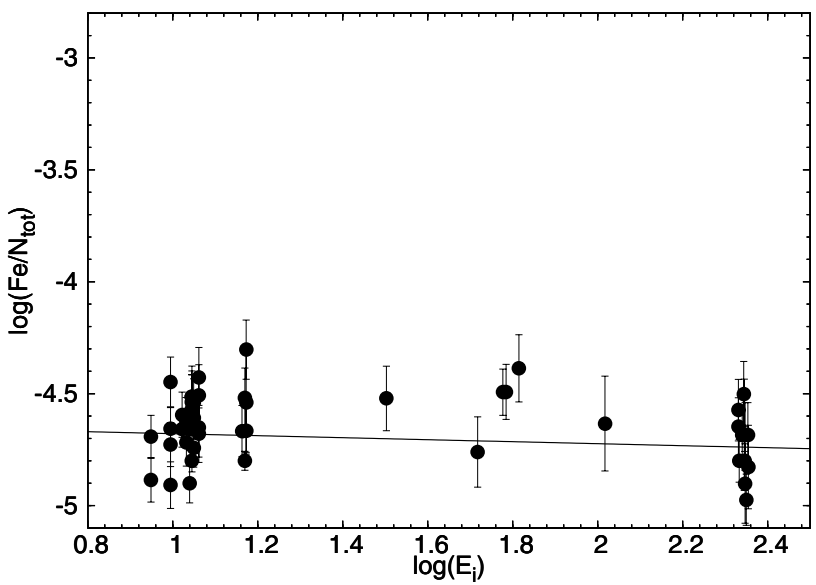

Fig. 3. Dependence of iron abundance on the lower level excitation potential of Fe II lines extracted from a) B267 and b) WF4-3485 spectra. The linear least-square fit to the data is shown by solid lines. Here the star B267 shows direct evidence of iron stratification, while WF4-3485 does not.

a)

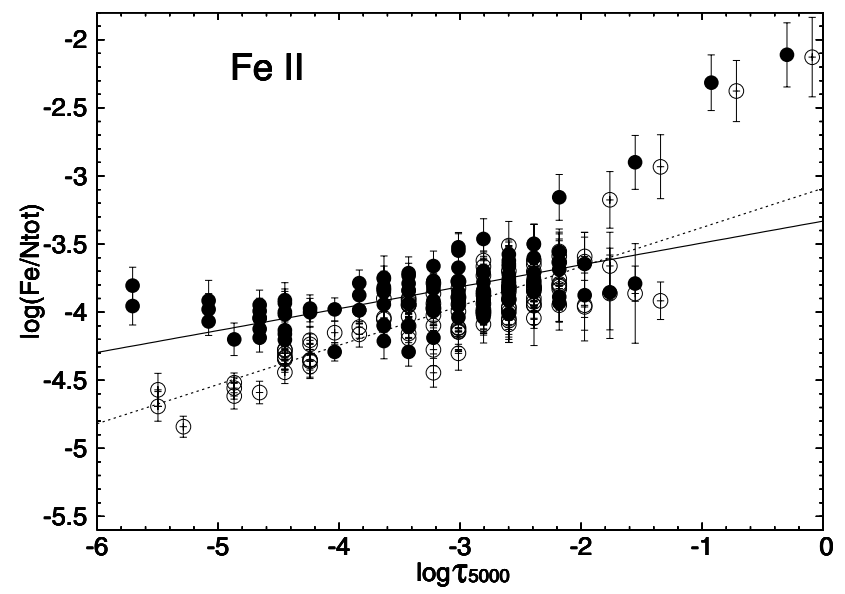

b)

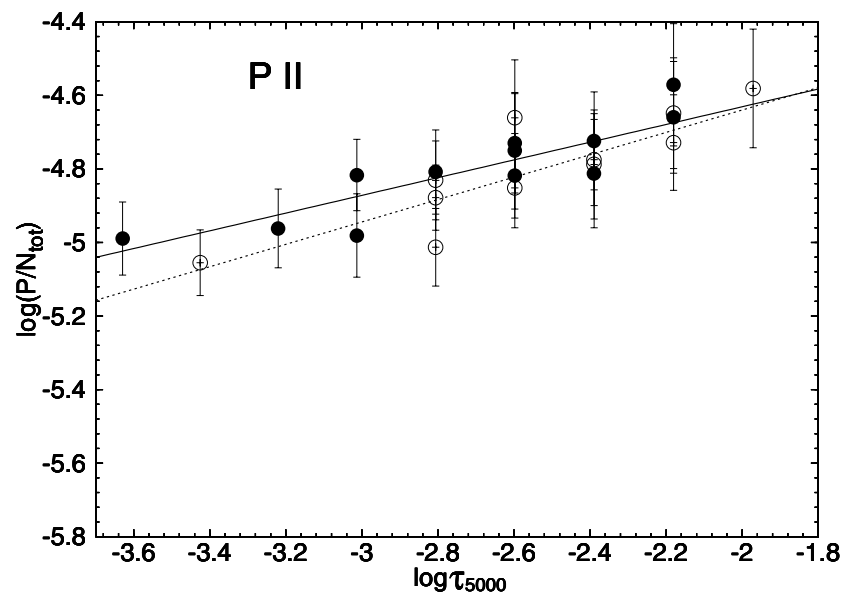

Fig. 4. The same as in Fig. 1, but for a) Fe II and b) P II lines extracted from the WF4-3085 spectrum. Here the visual strong rise in iron abundance at large optical depth manifests itself by four lines and may be real. Nevertheless, to draw the final conclusion we need more data for this range of optical depths.

Table 4. Slopes of vertical abundance stratification calculated for the linear least-square fit to the data assuming zero microturbulence.

\begin{tabular}{|c|c|c|c|c|c|c|}
\hline \multirow[t]{2}{*}{ Cluster/Star } & \multicolumn{2}{|c|}{ Slopes of $\log \left(\mathrm{Fe} / N_{\text {tot }}\right)$ vs. } & \multirow[t]{2}{*}{$\bar{n}$} & \multicolumn{2}{|c|}{ Slopes of $\log \left(\mathrm{P} / N_{\text {tot }}\right) \mathrm{vs}$. } & \multirow[t]{2}{*}{$n$} \\
\hline & $\log E_{i}$ & $\log \tau_{5000}$ & & $\log E_{i}$ & $\log \tau_{5000}$ & \\
\hline M 13/WF2-2541 & $0.18 \pm 0.04$ & $0.17 \pm 0.03$ & 53 & $-0.67 \pm 0.31$ & $-0.14 \pm 0.06$ & 16 \\
\hline M 13/WF4-3085 & $0.10 \pm 0.03$ & $0.15 \pm 0.02$ & 117 & $0.54 \pm 0.31$ & $0.24 \pm 0.04$ & 12 \\
\hline M 13/WF4-3485 & $-0.06 \pm 0.03$ & $-0.02 \pm 0.03$ & 50 & $\ldots$ & $\ldots$ & $\ldots$ \\
\hline M 15/B84 & $0.04 \pm 0.05$ & $0.03 \pm 0.04$ & 25 & ... $>$ & $\ldots$ &. \\
\hline М 15/B267 & $049+006$ & $033+003$ & 46 & Slopes of 1 & $\left.\mathrm{Ti} / N_{\text {tot }}\right)$ vs. & 16 \\
\hline M 15/B279 & $0.23 \pm 0.04$ & $0.23 \pm 0.02$ & 71 & $0.21 \pm 0.11$ & $0.30 \pm 0.08$ & 11 \\
\hline
\end{tabular}

velocity amplifies the iron stratification, the stratification obtained for iron in the first four stars studied with $\xi=0 \mathrm{~km} \mathrm{~s}^{-1}$ can be considered to be a lower limit to the possible stratification in these stars. A more detailed study including abundance stratification in the calculation of the synthesized spectra might shed some light on this strange behaviour, but this is outside of the scope of the present paper.

Figure $1 \mathrm{~b}$ indicates that B267 shows a possible signature of vertical stratification of the titanium abundance. The respective slopes of $\mathrm{Ti}$ abundance versus $\log E_{i}$ and $\log \tau_{5000}$ are significantly higher than zero for this star and are statistically significant (see Table 4). For B279, we can not confidently conclude that stratification exists since the slope of the abundance with respect to $\log E_{i}$ becomes weak when using either solar abundances or assuming a $T_{\text {eff }}$ increase of $1000 \mathrm{~K}$. The slope of $\mathrm{Ti}$ abundance with respect to $\log \tau_{5000}$ also becomes weak in the model assuming a $T_{\text {eff }}$ increase of $1000 \mathrm{~K}$. It should be noted that the Ti lines in B279 do not sample a large portion of the atmosphere and this fact renders the detection of stratification more difficult. 
a)

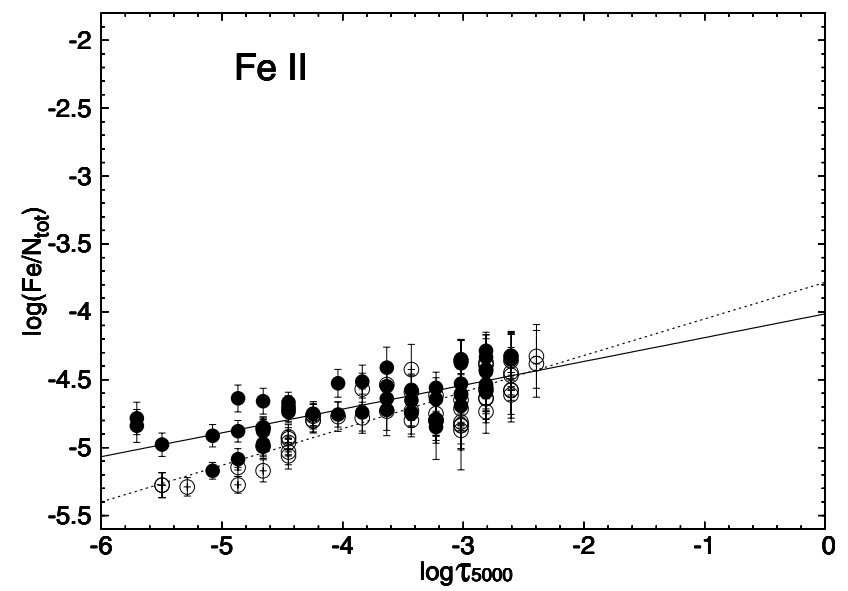

b)

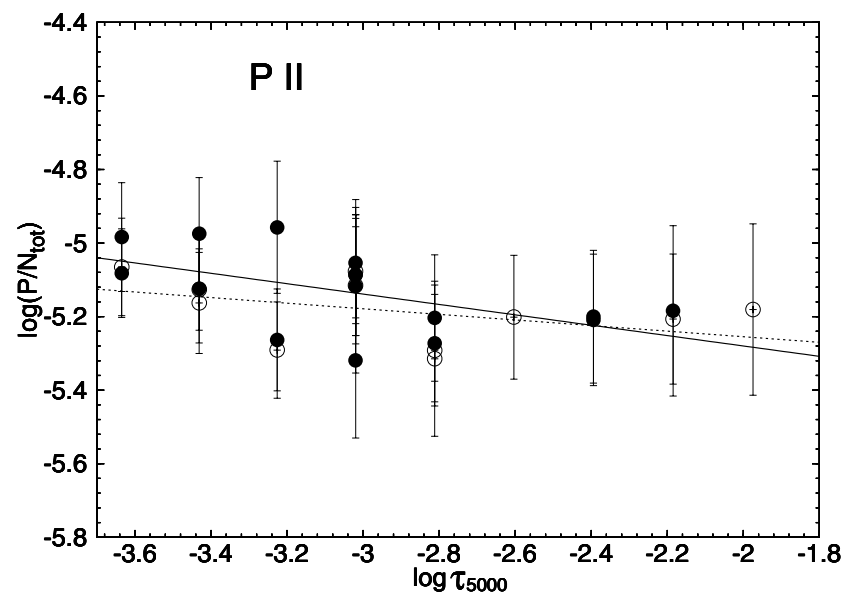

Fig. 5. The same as in Fig. 4, but for lines extracted from WF2-2541 spectrum.

a)

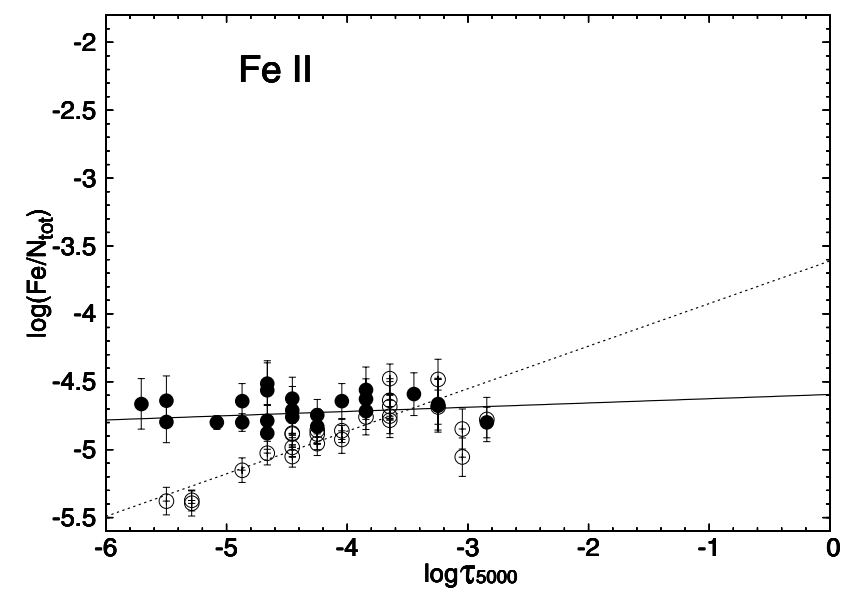

b)

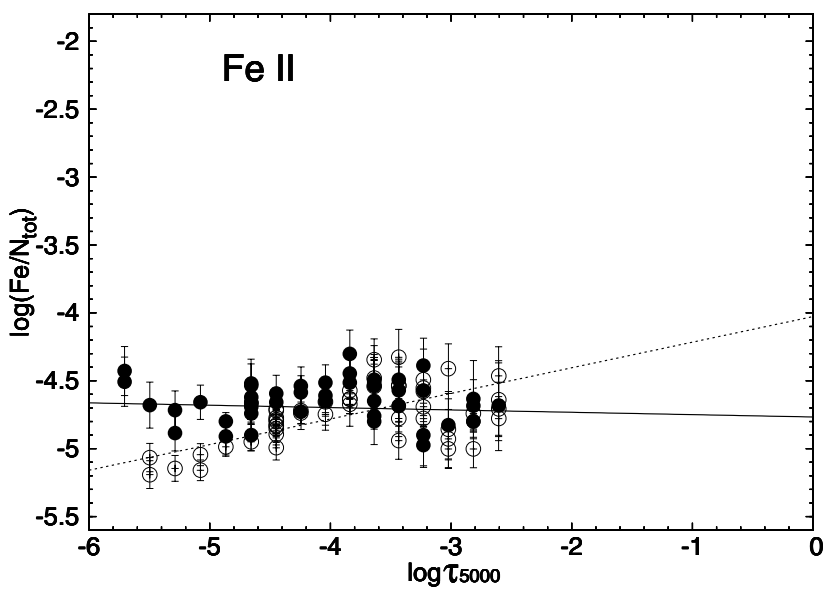

Fig. 6. The same as in Fig. 1, but for Fe II lines extracted for a) B84 and b) WF4-3485.

Table 5. Characteristics of our sample of hot BHB stars obtained from spectral simulations.

\begin{tabular}{|c|c|c|c|c|c|c|c|c|c|}
\hline \multirow[t]{2}{*}{ Cluster/Star } & \multirow{2}{*}{$\begin{array}{c}v \sin i \\
\mathrm{~km} \mathrm{~s}^{-1}\end{array}$} & \multirow{2}{*}{$\begin{array}{c}V_{\mathrm{r}} \\
\mathrm{km} \mathrm{s}^{-1}\end{array}$} & \multirow{2}{*}{$\begin{array}{c}\xi_{\min } \\
\mathrm{km} \mathrm{s}^{-1}\end{array}$} & \multicolumn{3}{|c|}{$\overline{[\mathrm{Fe} / \mathrm{H}]}$} & \multicolumn{3}{|c|}{$\overline{\mathrm{P} / \mathrm{H}]}$} \\
\hline & & & & $\xi=0 \mathrm{~km} \mathrm{~s}^{-1}$ & $\xi=2 \mathrm{~km} \mathrm{~s}^{-1}$ & $n$ & $\xi=0 \mathrm{~km} \mathrm{~s}^{-1}$ & $\xi=2 \mathrm{~km} \mathrm{~s}^{-1}$ & $n$ \\
\hline M 13/WF2-2541 & $2.4 \pm 0.5$ & $-257.3 \pm 0.5$ & $0.0+0.3$ & $-0.12 \pm 0.20$ & $-0.19 \pm 0.26$ & 53 & $+1.51 \pm 0.11$ & $+1.46 \pm 0.10$ & 16 \\
\hline M 13/WF4-3085 & $3.4 \pm 0.8$ & $-255.4 \pm 0.5$ & $0.5 \pm 0.3$ & $+0.72 \pm 0.29$ & $+0.59 \pm 0.37$ & 117 & $+1.84 \pm 0.13$ & $+1.84 \pm 0.15$ & 12 \\
\hline M 13/WF4-3485 & $3.0 \pm 0.9$ & $-246.9 \pm 0.9$ & $1.5 \pm 0.3$ & $-0.04 \pm 0.50$ & $-0.17 \pm 0.27$ & 50 & $\ldots$ & $\ldots$ & $\ldots$ \\
\hline M 15/B84 & $4.0 \pm 1.3$ & $-108.3 \pm 0.4$ & $0.0+0.3$ & $-0.14 \pm 0.10$ & $-0.35 \pm 0.24$ & 25 & $\cdots$ & & .. \\
\hline & & & & & & & \multicolumn{3}{|c|}{$[\mathrm{Ti} / \mathrm{H}]$} \\
\hline M 15/B267 & $6.2 \pm 1.2$ & $-114.7 \pm 0.7$ & $0.5 \pm 0.3$ & $+0.45 \pm 0.37$ & $+0.21 \pm 0.51$ & 46 & $+0.09 \pm 0.20$ & $-0.08 \pm 0.24$ & 16 \\
\hline
\end{tabular}

It is clear that phosphorous shows no clear signs of stratification in WF2-2541. For WF4-3085 we cannot make firm conclusions concerning phosphorous stratification since its abundance variation in the range of optical depths under consideration is only approximately 0.4 dex. Also, the slope of its abundance with respect to $\log E_{i}$ is not statistically significant.

\section{Mean abundances and velocities}

The mean photospheric abundances derived for the selected BHB stars from an analysis of the available iron, titanium and phosphorus lines are reported in Table 5. For each chemical element, three columns are shown containing the mean abundance for simulations with microturbulent velocity $\xi=0$ and $2 \mathrm{~km} \mathrm{~s}^{-1}$ respectively, and the number of analyzed line profiles. The reported uncertainties are equal to the standard deviation calculated from the results of individual line simulations for all lines considered.

The derived heliocentric radial and projected rotation velocities as well as microturbulent velocities (see Table 5) are generally in agreement with the data provided by Behr (2003b) for these stars. Some inconsistencies are found between $v \sin i$ values obtained for WF2-2541 $\left(v \sin i=0.0_{-0.0}^{+4.07} \mathrm{~km} \mathrm{~s}^{-1}\right)$ and B279 $\left(v \sin i=5.92_{-1.69}^{+1.6} \mathrm{~km} \mathrm{~s}^{-1}\right)$, but they are within the respective 
error bars given by Behr (2003b). The precision of our velocity estimates appears to be comparatively higher because of a more stringent selection of analysed line profiles. Our measurements of the average abundance of iron, titanium and phosphorus also agree with the corresponding values published by Behr (2003b), taking into account the error bars and the value of the applied microturbulent velocity. Small differences between our results and abundances from the aforementioned paper are not surprising. Our average abundance is calculated with the individual abundances obtained from each line, while Behr (2003b) fitted the whole spectrum of each element to obtain its abundance.

\section{Discussion}

In this paper we continue our attempts to detect vertical abundance stratification in the atmospheres of BHB stars. After the report by Bonifacio et al. (1995) of the vertical stratification of helium in the atmosphere of Feige 86, it became clear that the abundances of other chemical species may also be stratified. We devoted special interest to iron because hot BHB stars usually have an enhanced iron abundance (e.g. Behr 2003b), suggesting that this element may be strongly affected by diffusion. Analysing the spectra of another hot BHB star HD 135485 (Khalack et al. 2007) we did not find direct evidence of iron stratification, but revealed strong signatures of sulfur depletion in the deeper atmospheric layers. However, HD 135485 is different from the other BHB stars in that its spectrum shows evidence of helium enrichment (in comparison with the solar abundance), while in the atmospheres of the other BHB stars helium is depleted.

Therefore, we directed our attention to BHB stars where the iron abundance is near the solar abundance or enhanced, and helium is depleted. The results obtained argue that at least three stars (B267 and B279 in M 15 and WF2-2541 in M 13) show clear signatures of vertical stratification of their iron abundance, while for WF4-3085 the results are suggestive, but not conclusive. The other two stars studied here (B84 in M 15 and WF4-3485 in M 13) do not show stratification of iron and their averaged iron abundance is close to solar (but is enhanced in comparison with its cluster value). B267 shows also a signature of vertical stratification of titanium (see Fig. 1b).

Since our simulations show that the turnup feature observed in the iron stratification profile is strongly dependent on microturbulent velocity, the value of the abundance at low optical depths is uncertain. Of course, if the theoretical framework supposes that these abundance gradients are due to atomic diffusion, microturbulence should be weak since a stable atmosphere is needed for diffusion to be dominant. It should be noted that for corresponding optical depths the abundance profile of iron is similar in the three BHB stars that exhibit stratification. The reason that the other two stars in our study do not show clear signs of iron stratification (B84 and WF4-3485) might be related to evolutionary effects or the presence of other competing hydrodynamical processes. The absence of Ti II and P II lines in their spectra might be evidence of this.
In conclusion, the results shown here add to the mounting evidence of the existence of vertical abundance stratification, and hence atomic diffusion, in the atmospheres of BHB stars.

Acknowledgements. This research was partially funded by the Natural Sciences and Engineering Research Council of Canada (NSERC). We thank the Réseau québécois de calcul de haute performance (RQCHP) for computing resources. G.A.W. acknowledges support from the Academic Research Programme (ARP) of the Department of National Defence (Canada). B.B.B. thanks all the dedicated people involved in the construction and operation of the Keck telescopes and HIRES spectrograph. He is also grateful to Judy Cohen, Jim McCarthy, George Djorgovski, and Pat Côté for their contributions of Keck observing time. We are grateful to Dr. T. Ryabchikova and Dr. L. Mashonkina for helpful discussions and suggestions.

\section{References}

Behr, B. B. 2003a, ApJS, 149, 67

Behr, B. B. 2003b, ApJS, 149, 101

Behr, B. B., Cohen, J. G., McCarthy, J. K., \& Djorgovski, S. G. 1999, ApJ, 517, L135

Behr, B. B., Djorgovski, S. G., Cohen, J. G., et al. 2000a, ApJ, 528, 849

Behr, B. B., Cohen, J. G., \& McCarthy, J. K. 2000b, ApJ, 531, L37

Bonifacio, P., Castelli, F., \& Hack, M. 1995, A\&AS, 110, 441

Fabbian, D., Recio-Blanco, A., Gratton, R. G., \& Piotto, G. 2005, A\&A, 434, 235

Ferraro, F. R., Paltrinieri, B., Fusi Pecci, F., et al. 1998, ApJ, 500, 311

Glaspey, J. W., Michaud, G., Moffat, A. F. J., \& Demers, S. 1989, ApJ, 339, 926

Grundahl, F., Vandenberg, D. A., \& Andersen, M. I. 1998, ApJ, 500, L179

Grundahl, F., Catelan, M., Landsman, W. B., et al. 1999, ApJ, 524, 242

Hauschildt, P. H., Baron, E., \& Allard, F. 1997, ApJ, 483, 390

Hui-Bon-Hoa, A., LeBlanc, F., \& Hauschildt, P. H. 2000, ApJ, 535, L43

Khalack, V., \& Wade, G. 2006, A\&A, 450, 1157

Khalack, V., LeBlanc, F., Bohlender, D., et al. 2007, A\&A, 466, 667

Khan, S. A., \& Shulyak, D. V. 2007, A\&A, 469, 1083

Kupka, F., Piskunov, N. E., Ryabchikova, T. A., et al. 1999, A\&AS, 138, 119

Landstreet, J. D. 1988, ApJ, 326, 967

Landstreet, J. D. 1998, Contrib. Astron. Obs. Scalnaté Pleso, 27, 350

McCarthy, J. K. 1990, in Proc. 2nd ESO/ST-ECF Data Analysis Workshop (Garching: ESO), 119

Michaud, G. 1970, ApJ, 160, 641

Moehler, S. 2004, Proc. IAU Symp. 224, ed. J. Zverko, W. W. Weiss, J. Ziznovsky, \& S. J. Adelman, 119

Moehler, S., \& Sweigart, A. V. 2006, A\&A, 455, 943

Moehler, S., Heber, U., \& DeBoer, K. S. 1995, A\&A, 294, 65

Moehler, S., Heber, U., \& Durrell, P. R. 1997a, A\&A, 317, L83

Moehler, S., Heber, U., \& Rupprecht, G. 1997b, A\&A, 319, 109

Moehler, S., Landsman, W. B., Sweigart, A. V., \& Grundal, F. 2003, A\&A, 405, 135

Pace, G., Recio-Blanco, A., Piotto, G., \& Momany, Y. 2006, A\&A, 452, 493

Peterson, R. C., Rood, R. T., \& Crocker, D. A. 1995, ApJ, 453, 214

Pickering, J. C., Thorne, A. P., \& Perez, R. 2001, ApJS, 132, 403

Press, W. H., Teukolsky, S. A., Vetterling, W. T., \& Flannery, B. P. 1992, Numerical recipes in C: the art of scientific computing, 2nd Ed. (Cambridge University Press), 995

Raassen, A. J. J., \& Uylings, P. H. M. 1998, A\&A, 340, 300

Recio-Blanco, A., Piotto, G., Aparicio, A., \& Renzini, A. 2004, A\&A, 417, 597 Ryabchikova, T. A., Piskunov, N. E., Stempels, H. C., Kupka, F., \& Weiss, W. W. 1999, in Proc. of the 6th International Colloquium om Atomic Spectra and Oscillator Strengths, Victoria BC, Phys. Scr. T83, 162

Sandage, A. R., \& Wallerstein, G. 1960, ApJ, 131, 598

Shortridge, K. 1993, The Figaro 2.4 Manual

Wade, G. A., Bagnulo, S., Kochukhov, O., et al. 2001, A\&A, 374, 265 


\section{Online Material}


V. R. Khalack et al.: Search for vertical stratification of metals in atmospheres of BHB stars, Online Material p 2

Table 3. List of iron spectral lines used for the abundance analysis.

\begin{tabular}{|c|c|c|c|c|c|c|c|c|c|c|}
\hline$\lambda, \AA$ & $\log g f$ & $E_{i}, \mathrm{~cm}^{-1}$ & $\log \gamma_{\mathrm{rad}}$ & Ref. & \multicolumn{5}{|c|}{ Object name } & \\
\hline & & Fe II & & & WF2-2541 & WF4-3085 & WF2-3585 & B84 & B267 & B279 \\
\hline 3903.756 & -1.555 & 60807.23 & 8.99 & $\mathrm{R} \& \mathrm{U}$ & & $\mathrm{X}$ & & & & \\
\hline 3906.035 & -1.704 & 44929.55 & 8.72 & $R \& U$ & & $\mathrm{x}$ & $\mathrm{x}$ & & & $\mathrm{x}$ \\
\hline 3918.528 & -2.485 & 47674.72 & 8.55 & $R \& U$ & & $\mathrm{x}$ & & & & $\mathrm{x}$ \\
\hline 3920.635 & -1.335 & 60625.45 & 9.01 & $R \& U$ & & $\mathrm{x}$ & $\mathrm{x}$ & & $\mathrm{x}$ & $\mathrm{x}$ \\
\hline 3924.838 & -1.103 & 78137.36 & 8.93 & $\mathrm{R} \& \mathrm{U}$ & & $\mathrm{x}$ & & & & \\
\hline 3938.970 & -1.932 & 47674.72 & 8.61 & $R \& U$ & & $\mathrm{x}$ & & & & $\mathrm{x}$ \\
\hline 3945.210 & -4.440 & 13673.18 & 8.46 & $R \& U$ & & & & & & $\mathrm{x}$ \\
\hline 4002.083 & -4.481 & 22409.85 & 8.53 & $R \& U$ & & $\mathrm{x}$ & & & & \\
\hline 4002.543 & -2.072 & 48039.09 & 8.68 & $\mathrm{R} \& \mathrm{U}$ & & $\mathrm{x}$ & & & & \\
\hline 4016.367 & -1.420 & 75600.93 & 9.01 & $R \& U$ & & $\mathrm{x}$ & & & & \\
\hline 4024.547 & -2.439 & 36252.92 & 8.49 & $R \& U$ & & $\mathrm{x}$ & $\mathrm{x}$ & & $\mathrm{x}$ & $\mathrm{x}$ \\
\hline 4032.945 & -1.920 & 79331.50 & 9.18 & $R \& U$ & & $\mathrm{x}$ & & & & $\mathrm{x}$ \\
\hline 4044.012 & -2.671 & 44929.55 & 8.70 & $R \& U$ & & & & & & $\mathrm{x}$ \\
\hline 4048.832 & -2.381 & 44917.07 & 8.73 & $R \& U$ & & $\mathrm{x}$ & & & $\mathrm{x}$ & $\mathrm{x}$ \\
\hline 4122.668 & -3.300 & 20830.58 & 8.49 & $\mathrm{R} \& \mathrm{U}$ & & $\mathrm{x}$ & & $\mathrm{x}$ & & \\
\hline 4128.748 & -3.578 & 20830.58 & 8.61 & $R \& U$ & & $\mathrm{x}$ & & & & $\mathrm{x}$ \\
\hline 4173.461 & -2.617 & 20830.58 & 8.61 & $R \& U$ & $\mathrm{x}$ & $\mathrm{x}$ & $\mathrm{x}$ & $\mathrm{x}$ & $\mathrm{x}$ & \\
\hline 4177.618 & -3.776 & 73395.93 & 8.61 & $R \& U$ & & $\mathrm{x}$ & & $\mathrm{x}$ & & $\mathrm{x}$ \\
\hline 4177.692 & -3.449 & 20516.96 & 8.61 & $R \& U$ & & $\mathrm{x}$ & & $\mathrm{x}$ & & $\mathrm{x}$ \\
\hline 4178.862 & -2.535 & 20830.58 & 8.49 & $R \& U$ & $\mathrm{x}$ & $\mathrm{x}$ & $\mathrm{x}$ & $\mathrm{x}$ & & $\mathrm{x}$ \\
\hline 4184.261 & -1.938 & 90397.87 & 8.35 & $R \& U$ & & $\mathrm{x}$ & & & & \\
\hline 4217.899 & -0.976 & 90777.81 & 8.51 & VALD & & & & & $\mathrm{x}$ & \\
\hline 4233.172 & -1.947 & 20830.58 & 8.61 & $R \& U$ & & $\mathrm{x}$ & $\mathrm{x}$ & & $\mathrm{x}$ & \\
\hline 4258.154 & -3.478 & 21812.06 & 8.48 & $R \& U$ & & $\mathrm{x}$ & & & & $\mathrm{x}$ \\
\hline 4258.340 & -4.301 & 21308.04 & 8.61 & $R \& U$ & & & & & & $\mathrm{x}$ \\
\hline 4263.869 & -1.696 & 62049.03 & 8.95 & $R \& U$ & & $\mathrm{x}$ & & & & \\
\hline 4273.326 & -3.303 & 21812.06 & 8.62 & $R \& U$ & $\mathrm{x}$ & $\mathrm{x}$ & $\mathrm{x}$ & & & $\mathrm{x}$ \\
\hline 4286.280 & -1.730 & 62171.61 & 8.96 & $R \& U$ & & $\mathrm{x}$ & & & & \\
\hline 4296.572 & -2.933 & 21812.06 & 8.49 & $\mathrm{R} \& \mathrm{U}$ & & $\mathrm{x}$ & $\mathrm{x}$ & $\mathrm{x}$ & & $\mathrm{x}$ \\
\hline 4303.176 & -2.511 & 21812.06 & 8.61 & $\mathrm{R} \& \mathrm{U}$ & $\mathrm{x}$ & $\mathrm{x}$ & $\mathrm{x}$ & & $\mathrm{x}$ & \\
\hline 4314.979 & -3.193 & 38164.19 & 8.49 & $R \& U$ & & & & & $\mathrm{x}$ & $\mathrm{x}$ \\
\hline 4351.769 & -2.216 & 21812.06 & 8.61 & $R \& U$ & $\mathrm{x}$ & & $\mathrm{x}$ & & & \\
\hline 4357.584 & -2.010 & 49100.98 & 8.64 & $\mathrm{R} \& \mathrm{U}$ & & & & & $\mathrm{x}$ & \\
\hline 4361.205 & -2.827 & 62125.60 & 8.94 & $R \& U$ & & $\mathrm{x}$ & & & & \\
\hline 4361.247 & -2.264 & 49506.93 & 8.70 & $R \& U$ & & $\mathrm{x}$ & & & & \\
\hline 4369.411 & -3.584 & 22409.85 & 8.48 & $R \& U$ & & & & & & $\mathrm{x}$ \\
\hline 4384.319 & -3.684 & 21430.36 & 8.48 & $R \& U$ & & $\mathrm{x}$ & & & & $\mathrm{x}$ \\
\hline 4385.381 & -2.581 & 22409.85 & 8.62 & $R \& U$ & $\mathrm{x}$ & $\mathrm{x}$ & $\mathrm{x}$ & & & \\
\hline 4416.830 & -2.602 & 22409.85 & 8.61 & $\mathrm{R} \& \mathrm{U}$ & $\mathrm{x}$ & $\mathrm{x}$ & $\mathrm{x}$ & & $\mathrm{x}$ & $\mathrm{x}$ \\
\hline 4451.551 & -1.907 & 49506.93 & 8.74 & $R \& U$ & & $\mathrm{x}$ & $\mathrm{x}$ & & $\mathrm{x}$ & $\mathrm{x}$ \\
\hline 4455.266 & -2.000 & 50212.83 & 8.58 & $R \& U$ & & & & & & $\mathrm{x}$ \\
\hline 4461.694 & -4.002 & 63272.98 & 9.02 & $R \& U$ & $\mathrm{x}$ & $\mathrm{x}$ & & & & $\mathrm{x}$ \\
\hline 4461.706 & -2.065 & 50212.83 & 8.62 & $\mathrm{R} \& \mathrm{U}$ & $\mathrm{x}$ & $\mathrm{x}$ & & & & $\mathrm{x}$ \\
\hline 4472.929 & -3.531 & 22939.36 & 8.48 & $\mathrm{R} \& \mathrm{U}$ & & $\mathrm{x}$ & $\mathrm{x}$ & & & $\mathrm{x}$ \\
\hline 4489.183 & -2.971 & 22810.36 & 8.49 & $R \& U$ & $\mathrm{x}$ & & $\mathrm{x}$ & & & $\mathrm{x}$ \\
\hline 4491.405 & -2.755 & 23031.30 & 8.48 & $R \& U$ & & $\mathrm{x}$ & $\mathrm{x}$ & $\mathrm{x}$ & $\mathrm{x}$ & $\mathrm{x}$ \\
\hline 4493.529 & -1.555 & 63876.32 & 9.00 & $\mathrm{R} \& \mathrm{U}$ & & $\mathrm{x}$ & & & & \\
\hline
\end{tabular}


V. R. Khalack et al.: Search for vertical stratification of metals in atmospheres of BHB stars, Online Material p 3

Table 3. continued.

\begin{tabular}{|c|c|c|c|c|c|c|c|c|c|c|}
\hline$\lambda, \AA$ & $\overline{\log g f}$ & $E_{i}, \mathrm{~cm}^{-1}$ & $\log \gamma_{\mathrm{rad}}$ & Ref. & & $\overline{\text { Obje }}$ & name & & & \\
\hline & & Fe II & & & WF2-2541 & WF4-3085 & WF2-3585 & B84 & B267 & B279 \\
\hline 4508.214 & -2.589 & 63948.79 & 9.01 & R\&U & $\mathrm{x}$ & $\mathrm{x}$ & $\mathrm{x}$ & & & $\mathrm{x}$ \\
\hline 4508.288 & -2.349 & 23031.30 & 8.62 & $\mathrm{R} \& \mathrm{U}$ & $\mathrm{x}$ & $\mathrm{x}$ & $\mathrm{x}$ & & & $\mathrm{x}$ \\
\hline 4515.339 & -2.540 & 22939.36 & 8.49 & $\mathrm{R} \& \mathrm{U}$ & & $\mathrm{x}$ & $\mathrm{x}$ & $\mathrm{x}$ & $\mathrm{x}$ & \\
\hline 4520.224 & -2.617 & 22637.21 & 8.49 & $R \& U$ & $\mathrm{x}$ & $\mathrm{x}$ & & & & $\mathrm{x}$ \\
\hline 4522.634 & -2.169 & 22939.36 & 8.61 & $\mathrm{R} \& \mathrm{U}$ & $\mathrm{x}$ & $\mathrm{x}$ & $\mathrm{x}$ & $\mathrm{x}$ & $\mathrm{x}$ & \\
\hline 4534.168 & -3.364 & 23031.30 & 8.49 & $\mathrm{R} \& \mathrm{U}$ & $\mathrm{x}$ & $\mathrm{x}$ & & & & \\
\hline 4541.524 & -2.973 & 23031.30 & 8.61 & $\mathrm{R} \& \mathrm{U}$ & & $\mathrm{x}$ & $\mathrm{x}$ & $\mathrm{x}$ & & $\mathrm{x}$ \\
\hline 4549.192 & -1.767 & 47674.72 & 8.70 & $\mathrm{R} \& \mathrm{U}$ & $\mathrm{x}$ & $\mathrm{x}$ & $\mathrm{x}$ & & $\mathrm{x}$ & \\
\hline 4549.474 & -2.016 & 22810.36 & 8.61 & $\mathrm{R} \& \mathrm{U}$ & $\mathrm{x}$ & $\mathrm{x}$ & $\mathrm{x}$ & & & \\
\hline 4555.893 & -2.421 & 22810.36 & 8.49 & $\mathrm{R} \& \mathrm{U}$ & $\mathrm{x}$ & $\mathrm{x}$ & $\mathrm{x}$ & $\mathrm{x}$ & $\mathrm{x}$ & \\
\hline 4576.340 & -2.976 & 22939.36 & 8.61 & $\mathrm{R} \& \mathrm{U}$ & & & $\mathrm{x}$ & & & $\mathrm{x}$ \\
\hline 4579.527 & -2.343 & 50212.83 & 8.64 & $\mathrm{R} \& \mathrm{U}$ & & & & & $\mathrm{x}$ & $\mathrm{x}$ \\
\hline 4582.835 & -3.224 & 22939.36 & 8.49 & $\mathrm{R} \& \mathrm{U}$ & $\mathrm{x}$ & $\mathrm{x}$ & $\mathrm{x}$ & $\mathrm{x}$ & $\mathrm{x}$ & $\mathrm{x}$ \\
\hline 4583.837 & -1.867 & 22637.21 & 8.61 & $\mathrm{R} \& \mathrm{U}$ & $\mathrm{x}$ & $\mathrm{x}$ & $\mathrm{x}$ & $\mathrm{x}$ & $\mathrm{x}$ & \\
\hline 4596.015 & -1.956 & 50212.83 & 8.74 & $\mathrm{R} \& \mathrm{U}$ & $\mathrm{x}$ & $\mathrm{x}$ & & & & $\mathrm{x}$ \\
\hline 4598.494 & -1.512 & 62945.04 & 9.00 & $\mathrm{R} \& \mathrm{U}$ & & $\mathrm{x}$ & & & & \\
\hline 4620.521 & -3.315 & 22810.36 & 8.61 & $\mathrm{R} \& \mathrm{U}$ & $\mathrm{x}$ & $\mathrm{x}$ & & $\mathrm{x}$ & & $\mathrm{x}$ \\
\hline 4628.786 & -1.724 & 63272.98 & 9.01 & $\mathrm{R} \& \mathrm{U}$ & & $\mathrm{x}$ & & & & \\
\hline 4629.339 & -2.478 & 22637.21 & 8.48 & $\mathrm{R} \& \mathrm{U}$ & $\mathrm{x}$ & $\mathrm{x}$ & $\mathrm{x}$ & & & $\mathrm{x}$ \\
\hline 4635.316 & -1.578 & 48039.09 & 8.73 & $\mathrm{R} \& \mathrm{U}$ & $\mathrm{x}$ & $\mathrm{x}$ & $\mathrm{x}$ & $\mathrm{x}$ & $\mathrm{x}$ & $\mathrm{x}$ \\
\hline 4656.981 & -3.643 & 23317.63 & 8.61 & $\mathrm{R} \& \mathrm{U}$ & & $\mathrm{x}$ & & & & \\
\hline 4666.758 & -3.368 & 22810.36 & 8.48 & $\mathrm{R} \& \mathrm{U}$ & & $\mathrm{x}$ & & & & \\
\hline 4731.453 & -3.127 & 23317.63 & 8.61 & $\mathrm{R} \& \mathrm{U}$ & & $\mathrm{x}$ & $\mathrm{x}$ & $\mathrm{x}$ & $\mathrm{x}$ & $\mathrm{x}$ \\
\hline 4798.673 & -1.862 & 83136.49 & 8.95 & $R \& U$ & & & $\mathrm{x}$ & & & \\
\hline 4826.683 & -0.512 & 82978.68 & 8.95 & $\mathrm{R} \& \mathrm{U}$ & & $\mathrm{x}$ & & & & \\
\hline 4913.181 & -1.238 & 82978.68 & 8.96 & $\mathrm{R} \& \mathrm{U}$ & & $\mathrm{x}$ & & & $\mathrm{x}$ & $\mathrm{x}$ \\
\hline 4913.292 & 0.019 & 82978.68 & 8.95 & $\mathrm{R} \& \mathrm{U}$ & & $\mathrm{x}$ & & & $\mathrm{x}$ & $\mathrm{x}$ \\
\hline 4923.927 & -1.504 & 23317.63 & 8.49 & $\mathrm{R} \& \mathrm{U}$ & $\mathrm{x}$ & $\mathrm{x}$ & $\mathrm{x}$ & $\mathrm{x}$ & $\mathrm{x}$ & $\mathrm{x}$ \\
\hline 4948.096 & -0.239 & 83136.49 & 8.99 & $\mathrm{R} \& \mathrm{U}$ & & $\mathrm{x}$ & & & & \\
\hline 4948.793 & -0.043 & 83459.67 & 9.01 & $\mathrm{R} \& \mathrm{U}$ & & $\mathrm{x}$ & & & & \\
\hline 4951.584 & 0.198 & 83136.49 & 8.96 & $\mathrm{R} \& \mathrm{U}$ & & $\mathrm{x}$ & $\mathrm{x}$ & & & \\
\hline 4958.822 & -0.693 & 83713.54 & 8.95 & $\mathrm{R} \& \mathrm{U}$ & & $\mathrm{x}$ & & & & \\
\hline 4977.035 & -0.041 & 83558.54 & 9.00 & $\mathrm{R} \& \mathrm{U}$ & $\mathrm{x}$ & $\mathrm{x}$ & & & & \\
\hline 4977.923 & -0.606 & 83308.19 & 9.01 & $\mathrm{R} \& \mathrm{U}$ & & $\mathrm{x}$ & & & & \\
\hline 4984.488 & 0.074 & 83308.19 & 9.01 & $\mathrm{R} \& \mathrm{U}$ & & $\mathrm{x}$ & & & & \\
\hline 4990.509 & 0.193 & 83308.19 & 8.99 & $\mathrm{R} \& \mathrm{U}$ & & $\mathrm{x}$ & & & & \\
\hline 5001.864 & 0.010 & 31302.42 & 7.97 & $\mathrm{R} \& \mathrm{U}$ & & $\mathrm{x}$ & $\mathrm{x}$ & $\mathrm{x}$ & $\mathrm{x}$ & $\mathrm{x}$ \\
\hline 5001.959 & 0.916 & 82978.68 & 8.93 & $\mathrm{R} \& \mathrm{U}$ & $\mathrm{x}$ & $\mathrm{x}$ & $\mathrm{x}$ & $\mathrm{x}$ & $\mathrm{x}$ & $\mathrm{x}$ \\
\hline 5004.195 & 0.504 & 82853.66 & 8.93 & $\mathrm{R} \& \mathrm{U}$ & $\mathrm{x}$ & $\mathrm{x}$ & & & $\mathrm{x}$ & $\mathrm{x}$ \\
\hline 5006.841 & -0.260 & 83713.54 & 8.93 & $\mathrm{R} \& \mathrm{U}$ & & $\mathrm{x}$ & & & & \\
\hline 5007.447 & -0.435 & 83726.36 & 8.94 & $\mathrm{R} \& \mathrm{U}$ & & $\mathrm{x}$ & & & & \\
\hline 5007.739 & -0.273 & 82978.68 & 9.03 & $\mathrm{R} \& \mathrm{U}$ & & $\mathrm{x}$ & & & & \\
\hline 5018.440 & -1.345 & 23317.63 & 8.49 & $\mathrm{R} \& \mathrm{U}$ & $\mathrm{x}$ & $\mathrm{x}$ & $\mathrm{x}$ & $\mathrm{x}$ & $\mathrm{x}$ & $\mathrm{x}$ \\
\hline 5021.594 & -0.189 & 82978.68 & 9.05 & $\mathrm{R} \& \mathrm{U}$ & & $\mathrm{x}$ & & & & \\
\hline 5022.420 & -0.066 & 83459.67 & 9.01 & $\mathrm{R} \& \mathrm{U}$ & & $\mathrm{x}$ & & & & \\
\hline 5022.792 & -0.077 & 82978.68 & 9.10 & $\mathrm{R} \& \mathrm{U}$ & $\mathrm{x}$ & $\mathrm{x}$ & & & & $\mathrm{x}$ \\
\hline 5026.806 & -0.427 & 83136.49 & 9.03 & $\mathrm{R} \& \mathrm{U}$ & & $\mathrm{x}$ & & & & \\
\hline
\end{tabular}


V. R. Khalack et al.: Search for vertical stratification of metals in atmospheres of BHB stars, Online Material p 4

Table 3. continued.

\begin{tabular}{|c|c|c|c|c|c|c|c|c|c|c|}
\hline$\lambda, \AA$ & $\log g f$ & $E_{i}, \mathrm{~cm}^{-1}$ & $\log \gamma_{\mathrm{rad}}$ & Ref. & \multicolumn{6}{|c|}{ Object name } \\
\hline & & Fe II & & & WF2-2541 & WF4-3085 & WF2-3585 & B84 & B267 & B279 \\
\hline 5029.097 & -0.615 & 83558.54 & 9.07 & $\mathrm{R \& U}$ & & $\mathrm{x}$ & & & & \\
\hline 5030.630 & 0.433 & 82978.68 & 9.02 & $R \& U$ & $\mathrm{x}$ & $\mathrm{x}$ & & & $\mathrm{x}$ & $\mathrm{x}$ \\
\hline 5032.712 & 0.107 & 83812.32 & 8.99 & $R \& U$ & $\mathrm{x}$ & $\mathrm{x}$ & & & & $\mathrm{x}$ \\
\hline 5034.003 & -0.793 & 83558.54 & 9.02 & $R \& U$ & & $\mathrm{x}$ & & & & \\
\hline 5035.708 & 0.639 & 82978.68 & 8.94 & $R \& U$ & $\mathrm{x}$ & $\mathrm{x}$ & $\mathrm{x}$ & $\mathrm{x}$ & $\mathrm{x}$ & $\mathrm{x}$ \\
\hline 5045.114 & 0.005 & 83136.49 & 9.05 & $R \& U$ & & $\mathrm{x}$ & & & $\mathrm{x}$ & \\
\hline 5047.641 & -0.216 & 83136.49 & 9.04 & $\mathrm{R} \& \mathrm{U}$ & & $\mathrm{x}$ & & & $\mathrm{x}$ & \\
\hline 5061.718 & 0.290 & 83136.49 & 9.06 & $\mathrm{R} \& \mathrm{U}$ & & & & & & $\mathrm{x}$ \\
\hline 5067.893 & -0.063 & 83308.19 & 9.06 & $\mathrm{R} \& \mathrm{U}$ & & $\mathrm{x}$ & & & & \\
\hline 5070.899 & 0.275 & 83136.49 & 9.02 & $R \& U$ & $\mathrm{x}$ & $\mathrm{x}$ & & & & $\mathrm{x}$ \\
\hline 5075.764 & 0.168 & 84326.91 & 8.94 & $R \& U$ & $\mathrm{x}$ & $\mathrm{x}$ & & & & $\mathrm{x}$ \\
\hline 5082.230 & -0.121 & 83990.06 & 9.00 & $R \& U$ & & $\mathrm{x}$ & & & $\mathrm{x}$ & \\
\hline 5089.214 & 0.025 & 83308.19 & 9.05 & $R \& U$ & & & & & & $\mathrm{x}$ \\
\hline 5097.271 & 0.315 & 83713.54 & 8.94 & $\mathrm{R} \& \mathrm{U}$ & $\mathrm{x}$ & $\mathrm{x}$ & & & & $\mathrm{x}$ \\
\hline 5100.607 & 0.234 & 83726.36 & 8.95 & $\mathrm{R} \& \mathrm{U}$ & $\mathrm{x}$ & $\mathrm{x}$ & $\mathrm{x}$ & & $\mathrm{x}$ & $\mathrm{x}$ \\
\hline 5100.727 & 0.724 & 83726.36 & 8.94 & $R \& U$ & $\mathrm{x}$ & $\mathrm{x}$ & $\mathrm{x}$ & & $\mathrm{x}$ & $\mathrm{x}$ \\
\hline 5106.097 & -0.961 & 83812.32 & 9.00 & $\mathrm{R} \& \mathrm{U}$ & & $\mathrm{x}$ & & & & \\
\hline 5106.109 & -0.234 & 83308.19 & 9.06 & $\mathrm{R} \& \mathrm{U}$ & & $\mathrm{x}$ & & & & \\
\hline 5107.547 & -0.609 & 83812.32 & 9.17 & $\mathrm{R} \& \mathrm{U}$ & & $\mathrm{x}$ & & & & \\
\hline 5117.034 & -0.033 & 84131.56 & 9.01 & $R \& U$ & & $\mathrm{x}$ & $\mathrm{x}$ & & & \\
\hline 5123.188 & -2.457 & 62125.60 & 8.49 & $R \& U$ & & $\mathrm{x}$ & & & & \\
\hline 5123.188 & -2.286 & 84131.56 & 8.99 & $\mathrm{R} \& \mathrm{U}$ & & $\mathrm{x}$ & & & & \\
\hline 5132.669 & -4.094 & 22637.21 & 8.54 & $\mathrm{R} \& \mathrm{U}$ & & $\mathrm{x}$ & & & & \\
\hline 5143.880 & -0.223 & 84266.56 & 9.00 & $R \& U$ & & $\mathrm{x}$ & & & & \\
\hline 5149.465 & 0.544 & 84266.56 & 8.92 & $R \& U$ & $\mathrm{x}$ & $\mathrm{x}$ & & & & \\
\hline 5166.582 & -0.059 & 84326.91 & 8.98 & $R \& U$ & & & & & & $\mathrm{x}$ \\
\hline 5169.033 & -1.250 & 23317.63 & 8.48 & $R \& U$ & $\mathrm{x}$ & $\mathrm{x}$ & $\mathrm{x}$ & $\mathrm{x}$ & $\mathrm{x}$ & $\mathrm{x}$ \\
\hline 5180.314 & -0.103 & 83812.32 & 9.00 & $R \& U$ & & $\mathrm{x}$ & & & & $\mathrm{x}$ \\
\hline 5194.892 & -0.103 & 84424.37 & 8.99 & $\mathrm{R} \& \mathrm{U}$ & & $\mathrm{x}$ & & & & \\
\hline 5197.568 & -2.105 & 83865.63 & 9.05 & VALD & $\mathrm{x}$ & $\mathrm{x}$ & $\mathrm{x}$ & $\mathrm{x}$ & $\mathrm{x}$ & \\
\hline 5197.577 & -2.348 & 26055.42 & 8.48 & $R \& U$ & $\mathrm{x}$ & $\mathrm{x}$ & $\mathrm{x}$ & $\mathrm{x}$ & $\mathrm{x}$ & \\
\hline 5199.122 & 0.107 & 83713.54 & 9.02 & $R \& U$ & $\mathrm{x}$ & $\mathrm{x}$ & & & & \\
\hline 5213.960 & -0.264 & 84527.78 & 9.01 & $\mathrm{R} \& \mathrm{U}$ & & $\mathrm{x}$ & & & & \\
\hline 5214.057 & -0.633 & 83713.54 & 9.04 & $R \& U$ & & $\mathrm{x}$ & & & & \\
\hline 5215.844 & -0.153 & 83726.36 & 9.22 & $R \& U$ & & & & & $\mathrm{x}$ & \\
\hline 5216.854 & 0.480 & 84710.68 & 8.96 & $\mathrm{R} \& \mathrm{U}$ & & $\mathrm{x}$ & $\mathrm{x}$ & & $\mathrm{x}$ & $\mathrm{x}$ \\
\hline 5216.863 & 0.659 & 84527.78 & 8.93 & $R \& U$ & & $\mathrm{x}$ & $\mathrm{x}$ & & $\mathrm{x}$ & $\mathrm{x}$ \\
\hline 5218.842 & -0.181 & 83726.36 & 9.10 & $R \& U$ & & $\mathrm{x}$ & & & & \\
\hline 5223.260 & -0.190 & 83812.32 & 9.04 & $R \& U$ & & & & & $\mathrm{x}$ & \\
\hline 5223.290 & -0.914 & 84266.56 & 9.09 & $R \& U$ & & & & & $\mathrm{x}$ & \\
\hline 5223.800 & -0.532 & 83713.54 & 9.01 & $R \& U$ & & $\mathrm{x}$ & & & & \\
\hline 5224.411 & -0.450 & 83990.06 & 9.09 & $\mathrm{R} \& \mathrm{U}$ & & $\mathrm{x}$ & & & & \\
\hline 5227.323 & 0.191 & 84844.83 & 8.93 & $\mathrm{R} \& \mathrm{U}$ & & & $\mathrm{x}$ & & & \\
\hline 5227.481 & 0.834 & 84296.83 & 8.91 & $R \& U$ & & & $\mathrm{x}$ & & & \\
\hline 5232.787 & -0.115 & 83726.36 & 8.93 & $\mathrm{R} \& \mathrm{U}$ & & $\mathrm{x}$ & & & & \\
\hline 5234.615 & -2.385 & 84266.56 & 8.98 & $R \& U$ & & $\mathrm{x}$ & $\mathrm{x}$ & $\mathrm{x}$ & $\mathrm{x}$ & $\mathrm{x}$ \\
\hline 5234.625 & -2.279 & 25981.63 & 8.49 & $R \& U$ & & $\mathrm{x}$ & $\mathrm{x}$ & $\mathrm{x}$ & $\mathrm{x}$ & $\mathrm{x}$ \\
\hline 5237.951 & 0.101 & 84266.56 & 9.11 & $R \& U$ & & $\mathrm{x}$ & $\mathrm{x}$ & & & \\
\hline
\end{tabular}


V. R. Khalack et al.: Search for vertical stratification of metals in atmospheres of BHB stars, Online Material p 5

Table 3. continued.

\begin{tabular}{|c|c|c|c|c|c|c|c|c|c|c|}
\hline$\lambda, \AA$ & $\log g f$ & $E_{i}, \mathrm{~cm}^{-1}$ & $\log \gamma_{\mathrm{rad}}$ & Ref. & \multicolumn{6}{|c|}{ Object name } \\
\hline & & Fe II & & & WF2-2541 & WF4-3085 & WF2-3585 & B84 & B267 & B279 \\
\hline 5247.952 & 0.550 & 84938.18 & 8.95 & R\&U & & $\mathrm{x}$ & $\mathrm{x}$ & & $\mathrm{x}$ & $\mathrm{x}$ \\
\hline 5251.211 & -0.638 & 84326.91 & 8.99 & $R \& U$ & & $\mathrm{x}$ & & & & \\
\hline 5251.233 & 0.442 & 84844.83 & 9.00 & $R \& U$ & & $\mathrm{x}$ & & & & \\
\hline 5254.929 & -3.336 & 26055.42 & 8.49 & $R \& U$ & & & $\mathrm{x}$ & & & \\
\hline 5260.259 & 1.069 & 84035.01 & 8.91 & $\mathrm{R} \& \mathrm{U}$ & & & $\mathrm{x}$ & $\mathrm{x}$ & & $\mathrm{x}$ \\
\hline 5262.317 & -0.370 & 85048.60 & 9.08 & $\mathrm{R} \& \mathrm{U}$ & & $\mathrm{x}$ & & & & \\
\hline 5264.812 & -3.132 & 26055.42 & 8.61 & $\mathrm{R} \& \mathrm{U}$ & & $\mathrm{x}$ & $\mathrm{x}$ & & & $\mathrm{x}$ \\
\hline 5272.397 & -2.009 & 48039.09 & 8.70 & $\mathrm{R} \& \mathrm{U}$ & & $\mathrm{x}$ & & & & $\mathrm{x}$ \\
\hline 5276.002 & -2.213 & 25805.33 & 8.49 & $\mathrm{R} \& \mathrm{U}$ & & $\mathrm{x}$ & $\mathrm{x}$ & $\mathrm{x}$ & $\mathrm{x}$ & $\mathrm{x}$ \\
\hline 5291.667 & 0.556 & 84527.78 & 9.00 & $\mathrm{R} \& \mathrm{U}$ & $\mathrm{x}$ & $\mathrm{x}$ & & & & $\mathrm{x}$ \\
\hline 5306.180 & 0.104 & 84870.86 & 9.06 & $\mathrm{R} \& \mathrm{U}$ & & & & & $\mathrm{x}$ & \\
\hline 5316.225 & 0.340 & 84035.14 & 8.92 & $\mathrm{R} \& \mathrm{U}$ & & & & & & $\mathrm{x}$ \\
\hline 5316.615 & -2.014 & 25428.78 & 8.48 & $R \& U$ & $\mathrm{x}$ & & & & & $\mathrm{x}$ \\
\hline 5316.784 & -2.783 & 25981.63 & 8.61 & $R \& U$ & $\mathrm{x}$ & & & & & $\mathrm{x}$ \\
\hline 5325.553 & -3.324 & 25981.63 & 8.49 & $R \& U$ & & $\mathrm{x}$ & $\mathrm{x}$ & & $\mathrm{x}$ & $\mathrm{x}$ \\
\hline 5339.585 & 0.540 & 84296.83 & 8.91 & $R \& U$ & $\mathrm{x}$ & $\mathrm{x}$ & $\mathrm{x}$ & & & \\
\hline 5362.869 & -2.616 & 25805.33 & 8.61 & $R \& U$ & $\mathrm{x}$ & & & & & \\
\hline 5362.967 & -0.137 & 84685.20 & 8.90 & $\mathrm{R} \& \mathrm{U}$ & $\mathrm{x}$ & & & & & \\
\hline 5427.826 & -1.580 & 54232.19 & 8.54 & $\mathrm{R} \& \mathrm{U}$ & $\mathrm{x}$ & & & & & \\
\hline 5429.988 & 0.438 & 85462.86 & 8.93 & $R \& U$ & $\mathrm{x}$ & & & & & \\
\hline 5465.931 & 0.352 & 85679.70 & 8.91 & $R \& U$ & $\mathrm{x}$ & & & & & \\
\hline 5492.079 & 0.089 & 85679.70 & 8.98 & $\mathrm{R} \& \mathrm{U}$ & $\mathrm{x}$ & & & & & \\
\hline 5506.195 & 0.849 & 84863.35 & 8.89 & $\mathrm{R} \& \mathrm{U}$ & $\mathrm{x}$ & & & & & \\
\hline 5507.072 & -0.082 & 84870.86 & 8.98 & $\mathrm{R} \& \mathrm{U}$ & $\mathrm{x}$ & & & & & \\
\hline 5510.779 & -0.092 & 85184.73 & 8.92 & $\mathrm{R} \& \mathrm{U}$ & $\mathrm{x}$ & & & & & \\
\hline 5544.763 & 0.129 & 84863.35 & 9.21 & $R \& U$ & $\mathrm{x}$ & & & & & \\
\hline 5645.392 & 0.176 & 85184.73 & 9.21 & $\mathrm{R} \& \mathrm{U}$ & $\mathrm{x}$ & & & & & \\
\hline & & Ti II & & & & & & & & \\
\hline 3900.539 & -0.200 & 9118.28 & 8.36 & Pic. & & & & & & $\mathrm{x}$ \\
\hline 3913.461 & -0.420 & 8997.78 & 8.37 & Pic. & & & & & $\mathrm{x}$ & $\mathrm{x}$ \\
\hline 4053.821 & -1.130 & 15265.69 & 8.38 & Pic. & & & & & $\mathrm{x}$ & \\
\hline 4163.644 & -0.130 & 20891.78 & 8.37 & Pic. & & & & & $\mathrm{x}$ & $\mathrm{x}$ \\
\hline 4290.215 & -0.850 & 9395.79 & 8.46 & Pic. & & & & & $\mathrm{x}$ & $\mathrm{x}$ \\
\hline 4294.094 & -0.930 & 8744.34 & 8.22 & Pic. & & & & & $\mathrm{x}$ & $\mathrm{x}$ \\
\hline 4300.042 & -0.440 & 9518.14 & 8.47 & Pic. & & & & & $\mathrm{x}$ & $\mathrm{x}$ \\
\hline 4301.922 & -1.150 & 9363.73 & 8.47 & Pic. & & & & & $\mathrm{x}$ & \\
\hline 4395.031 & -0.540 & 8744.34 & 8.21 & Pic. & & & & & $\mathrm{x}$ & $\mathrm{x}$ \\
\hline 4399.765 & -1.190 & 9975.99 & 8.46 & Pic. & & & & & $\mathrm{x}$ & \\
\hline 4443.801 & -0.720 & 8710.56 & 8.20 & Pic. & & & & & $\mathrm{x}$ & $\mathrm{x}$ \\
\hline 4468.507 & -0.600 & 9122.14 & 8.21 & VALD & & & & & $\mathrm{x}$ & \\
\hline 4501.270 & -0.684 & 8997.78 & 8.20 & VALD & & & & & $\mathrm{x}$ & $\mathrm{x}$ \\
\hline 4563.757 & -0.690 & 9851.00 & 8.22 & Pic. & & & & & $\mathrm{x}$ & $\mathrm{x}$ \\
\hline 4571.971 & -0.230 & 12677.10 & 8.37 & Pic. & & & & & & $\mathrm{x}$ \\
\hline 4805.085 & -0.960 & 16623.11 & 8.26 & VALD & & & & & $\mathrm{x}$ & \\
\hline 4911.195 & -0.610 & 25192.96 & 8.30 & Pic. & & & & & $\mathrm{x}$ & \\
\hline 5188.687 & -1.050 & 12758.26 & 8.22 & Pic. & & & & & $\mathrm{x}$ & \\
\hline
\end{tabular}


V. R. Khalack et al.: Search for vertical stratification of metals in atmospheres of BHB stars, Online Material p 6

Table 3. continued.

\begin{tabular}{|c|c|c|c|c|c|c|c|c|c|c|}
\hline$\lambda, \AA$ & $\log g f$ & $E_{i}, \mathrm{~cm}^{-1}$ & $\log \gamma_{\mathrm{rad}}$ & Ref. & \multicolumn{5}{|c|}{ Object name } & \\
\hline & & P II & & & WF2-2541 & WF4-3085 & WF2-3585 & B84 & B267 & B279 \\
\hline 4178.463 & -0.409 & 77671.28 & & VALD & $\mathrm{x}$ & $\mathrm{x}$ & & & & \\
\hline 4420.712 & -0.478 & 88893.22 & & VALD & $\mathrm{x}$ & $\mathrm{x}$ & & & & \\
\hline 4463.027 & 0.026 & 105553.90 & & VALD & & $\mathrm{x}$ & & & & \\
\hline 4468.000 & -0.208 & 105223.22 & & VALD & & $\mathrm{x}$ & & & & \\
\hline 4475.270 & 0.301 & 105553.90 & & VALD & $\mathrm{x}$ & $\mathrm{x}$ & & & & \\
\hline 4499.230 & 0.377 & 107922.93 & & VALD & $\mathrm{x}$ & $\mathrm{x}$ & & & & \\
\hline 4530.823 & -0.020 & 105303.87 & & VALD & $\mathrm{x}$ & $\mathrm{x}$ & & & & \\
\hline 4588.032 & 0.575 & 103343.94 & & VALD & $\mathrm{x}$ & $\mathrm{x}$ & & & & \\
\hline 4589.846 & 0.500 & 103166.50 & & VALD & & $\mathrm{x}$ & & & & \\
\hline 4602.069 & 0.799 & 103667.86 & & VALD & & $\mathrm{x}$ & & & & \\
\hline 4658.309 & -0.412 & 103665.56 & & VALD & & $\mathrm{x}$ & & & & \\
\hline 4943.497 & 0.083 & 103665.56 & & VALD & & $\mathrm{x}$ & & & & \\
\hline 5253.479 & 0.291 & 88893.22 & & VALD & $\mathrm{x}$ & & & & & \\
\hline 5296.077 & -0.134 & 87124.60 & & VALD & $\mathrm{x}$ & & & & & \\
\hline 5316.055 & -0.341 & 86743.96 & & VALD & $\mathrm{x}$ & & & & & \\
\hline 5344.729 & -0.329 & 86597.55 & & VALD & $\mathrm{x}$ & & & & & \\
\hline 5425.880 & 0.241 & 87124.11 & & VALD & $\mathrm{x}$ & & & & & \\
\hline 5499.697 & -0.495 & 87124.11 & & VALD & $\mathrm{x}$ & & & & & \\
\hline 6024.178 & 0.137 & 86745.03 & & VALD & $\mathrm{x}$ & & & & & \\
\hline 6034.039 & -0.209 & 86599.85 & & VALD & $\mathrm{x}$ & & & & & \\
\hline 6043.084 & 0.384 & 87124.11 & & VALD & $\mathrm{x}$ & & & & & \\
\hline 6165.598 & -0.469 & 87124.11 & & VALD & $\mathrm{x}$ & & & & & \\
\hline
\end{tabular}

R\&U 1998A\&A...340..300R Raassen \& Uylings

VALD 1999POBeo..65..223K Kupka \& Ryabchikova

Pic. 2001ApJS...132..403 Pickering, Thorne \& Perez

NIST 2002nla.work...80R Reader et al. 